\title{
Proposta de um consórcio intermunicipal na microrregião de saúde de Teófilo Otoni/Malacacheta para gestão de resíduos sólidos urbanos
}

\author{
Proposal for an inter-municipal consortium in the health micro-region of Teófilo \\ Otoni/Malacacheta for urban solid waste management
}

Propuesta de consorcio intermunicipal en la microrregión de salud de Teófilo Otoni / Malacacheta para la gestión de residuos sólidos urbanos

Recebido: 21/07/2021 | Revisado: 29/07/2021 | Aceito: 05/08/2021 | Publicado: 09/08/2021

Thadeu Ramalho da Silva

ORCID: https:// orcid.org/0000-0003-4224-9501 Universidade Federal dos Vales do Jequitinhonha e Mucuri, Brasil

E-mail: thadeu.silva@ufvjm.edu.br

Júnio Gomes dos Santos

ORCID: https://orcid.org/0000-0002-8466-8408 Universidade Federal dos Vales do Jequitinhonha e Mucuri, Brasil E-mail: juniolorentz@gmail.com

Eliana Nunes Hipólito

ORCID: https://orcid.org/0000-0001-5031-6407 Universidade Federal dos Vales do Jequitinhonha e Mucuri, Brasil E-mail: hipolitoeliana@gmail.com

Mauro Lúcio Franco

ORCID: https://orcid.org/0000-0003-2114-4399 Universidade Federal dos Vales do Jequitinhonha e Mucuri, Brasil E-mail:ml.franco@ufvjm.edu.br

Marcio Coutinho de Souza

ORCID: https://orcid.org/0000-0002-4238-1572 Universidade Federal dos Vales do Jequitinhonha e Mucuri, Brasil

E-mail: marcio.souza@ufvjm.edu.br

Wederson Marcos Alves

ORCID: https://orcid.org/0000-0002-1105-1300 Universidade Federal dos Vales do Jequitinhonha e Mucuri, Brasil E-mail: wederson.alves@ufvjm.edu.br

Alexandre Sylvio Vieira da Costa ORCID: https://orcid.org/0000-0001-7251-7816 Universidade Federal dos Vales do Jequitinhonha e Mucuri, Brasil E-mail: alexandre.costa@ufvjm.edu.br

Allan Castro Ferreira

ORCID: https://orcid.org/0000-0002-2779-247X

Universidade Federal dos Vales do Jequitinhonha e Mucuri, Brasil E-mail: allan.ferreira@ufvjm.edu.br

\begin{abstract}
Resumo
O crescimento da população mundial, principalmente na área urbana, aliado ao consumo exacerbado de bens e serviços, desencadeia o aumento da geração de resíduos sólidos urbanos (RSU) e constitui, assim, um grande problema ambiental. Para acompanhar as políticas públicas ambientais mundiais e buscar, mitigar os danos ao meio ambiente no Brasil, instituiu-se a Lei 12.305 de 2010 que definiu a Política Nacional de Resíduos Sólidos Urbanos (PNRS), a qual deve ser seguida por todos os gestores municipais. O objetivo do estudo é analisar a possibilidade do desenvolvimento de um consórcio intermunicipal na microrregião de saúde de Teófilo Otoni/Malacacheta para a gestão de RSU. Esta pesquisa é classificada como qualitativa, com finalidade descritiva, adotando-se procedimentos bibliográficos e documentais para realizar o levantamento das informações relacionadas ao estudo, com o intuito de verificar a possibilidade da implantação de um consórcio intermunicipal para a gestão de RSU na referida microrregião. $\mathrm{O}$ artigo está estruturado nas seguintes seções: introdução, problema e objetivos da pesquisa; referencial teórico; metodologia; considerações finais e referências. Conclui-se que é urgente a elaboração de uma proposta intermunicipal de Gestão Integrada de Resíduos Sólidos Urbanos (GIRSU), a fim de proporcionar uma parceria público e/ou privada que resolva o problema dos lixões nesta região em um curto espaço de tempo, sendo necessária uma estratégia de interlocução entre os gestores municipais. Dentre as discussões para sensibilização dos gestores municipais, além das questões de sustentabilidade e meio ambiente, deve ser levado ao conhecimento dos mesmos que além dos recursos recebidos pelo consórcio, existem outras fontes de receitas para a implementação de uma
\end{abstract}


GIRSU que vai nortear o novo modelo de educação ambiental para a população, que pode promover renda aos agentes envolvidos na segregação de reciclagem de resíduos, além de proteger o meio ambiente da microrregião.

Palavras-chave: Resíduos sólidos urbanos; Consórcios intermunicipais de RSU; Aterro de sanitários.

\begin{abstract}
The growth of the world population, mainly in the urban area, combined with the exacerbated consumption of goods and services, triggers an increase in the generation of urban solid waste (USW) and thus constitutes a major environmental problem. To follow global environmental public policies and seek to mitigate damage to the environment in Brazil, Law 12,305 of 2010 was instituted, which defined the National Policy on Urban Solid Waste (PNRS), which must be followed by all municipal managers. The aim of the study is to analyze the possibility of developing an inter-municipal consortium in the health microregion of Teófilo Otoni/Malacacheta for the management of MSW. This research is classified as qualitative, with descriptive purpose, adopting bibliographic and documentary procedures to carry out the survey of information related to the study, in order to verify the possibility of implementing an inter-municipal consortium for the management of MSW in that micro-region. The article is structured in the following sections: introduction, problem and research objectives; Theoretical Reference; methodology; final considerations and references. It is concluded that it is urgent to prepare an inter-municipal proposal for Integrated Urban Solid Waste Management (GIRSU), in order to provide a public and/or private partnership that solves the problem of landfills in this region in a short period of time. A dialogue strategy between municipal managers is necessary. Among the discussions to raise awareness of municipal managers, in addition to sustainability and environmental issues, they should be made aware that, in addition to the resources received by the consortium, there are other sources of revenue for the implementation of a GIRSU that will guide the new model environmental education for the population, which can promote income for agents involved in the segregation of waste recycling, in addition to protecting the environment of the micro-region.
\end{abstract}

Keywords: Urban solid waste; Inter-municipal RSU Consortia; Landfill of toilets.

\title{
Resumen
}

El crecimiento de la población mundial, principalmente en el área urbana, combinado con el consumo exacerbado de bienes y servicios, desencadena un aumento en la generación de residuos sólidos urbanos (RSU) y, por lo tanto, constituye un importante problema ambiental. Para seguir las políticas públicas ambientales globales y buscar mitigar los daños al medio ambiente en Brasil, se instituyó la Ley 12.305 de 2010, que definió la Política Nacional de Residuos Sólidos Urbanos (PNRS), que deben seguir todos los administradores municipales. El objetivo del estudio es analizar la posibilidad de desarrollar un consorcio intermunicipal en la microrregión de salud de Teófilo Otoni / Malacacheta para la gestión de RSU. Esta investigación se clasifica como cualitativa, con finalidad descriptiva, adoptando procedimientos bibliográficos y documentales para realizar el relevamiento de la información relacionada con el estudio, con el fin de verificar la posibilidad de implementar un consorcio intermunicipal para la gestión de RSU en esa microrregión. El artículo se estructura en los siguientes apartados: introducción, problema de investigación y objetivos; referencial teórico; metodología; consideraciones finales y referencias. Se concluye que es urgente elaborar una propuesta intermunicipal de Gestión Integrada de Residuos Sólidos Urbanos (GIRSU), con el fin de brindar una alianza pública y / o privada que resuelva el problema de los rellenos sanitarios en esta región en un corto período de tiempo. Es necesaria una estrategia de diálogo entre los gestores municipales. Entre las discusiones para concientizar a los gestores municipales, además de los temas de sostenibilidad y medio ambiente, se debe concienciar que, además de los recursos que recibe el consorcio, existen otras fuentes de ingresos para la implementación de un GIRSU que orientarán el nuevo modelo de educación ambiental para la población, que puede promover ingresos para los agentes involucrados en la segregación del reciclaje de residuos, además de proteger el medio ambiente de la microrregión.

Palabras clave: Residuos sólidos urbanos; Consorcios intermunicipales RSU; Vertedero de sanitarios.

\section{Introdução}

A intensificação do consumo humano proporciona ampla geração de resíduos sólidos urbanos (RSU). Todavia, esse crescimento pode não ser assistido pelo correto manejo dos materiais, e isso pode ocasionar situações que lesa a saúde humana e o meio ambiente (Freitas \& et al., 2019). Tendo em vista a intensificação do consumo e com o objetivo de reforçar as leis já existentes para proteção, do meio ambiente, foi aprovada a Lei 12.305 de 2010, que define a PNRS. A referida política, é um marco regulador na área de RSU no Brasil, tendo como intuito direcionar o país rumo a melhoria da qualidade de vida da sociedade, da preservação ambiental e da sustentabilidade.

A geração, a coleta, o tratamento e a destinação final dos RSU é uma temática de grande relevância para os administradores municipais. As diretrizes para uma gestão socialmente integrada de resíduos devem contemplar programas que 
apontem à implementação da redução, reutilização e reciclagem dos mesmos, através dos programas específicos de coleta seletiva e de educação ambiental nos municípios (Brandão \& Silva, 2011; Araújo et al., 2020).

O aterro sanitário é o método mais utilizado para a disposição adequada de RSU no Brasil (Abrelpe, 2020). Justificase a escolha dos aterros sanitários, devido à necessidade de se dar a acomodação correta com o devido tratamento, ainda com o reaproveitamento necessário dos compostos gerados, além de ser um dos compromissos estabelecidos na PNRS (Abrelpe, 2020). Os aterros podem ser individuais ou compartilhados, para municípios de pequeno porte é aconselhável utilizar-se de compartilhamento de aterros com outros municípios devido à complexidade para construir e manter um aterro sanitário individual e que atenda aos princípios da PNRS.

Dessa forma, surge o seguinte problema de pesquisa:

- O que poderia ser feito para que as cidades pertencentes à microrregião de Teofilo Otoni/Malacacheta deixassem de depositar seus RSU em lixões?

Buscando responder a esta pergunta, a pesquisa tem como objetivo analisar a possibilidade do desenvolvimento de um consórcio intermunicipal na microrregião de saúde de Teófilo Otoni/Malacacheta para a gestão de RSU. A proposta é que o aterro sanitário compartilhado atenda aos municípios de: Angelândia, Ataléia, Franciscópolis, Ladainha, Malacacheta, Novo Cruzeiro, Novo Oriente de Minas, Ouro Verde de Minas, Poté, Setubinha e Teófilo Otoni.

O presente o artigo está estruturado nas seguintes seções: (i) introdução, problema e objetivos da pesquisa; (ii) metodologia a qual caracteriza o estudo como abordagem qualitativa de natureza aplicada, finalidade descritiva e realizada por meio de pesquisa bibliográfica e documental para conhecer e analisar a referida microrregião; (iii) referencial teórico que apresenta a legislação sobre RSU no Brasil e as regiões político administrativas do Estado de Minas Gerais, a análise da gestão de RSU na microrregião de Teofilo Otoni/Malacacheta, e as experiências de consórcios compartilhados; e, por fim, (iiii) as considerações finais que incluiu sugestões de melhorias na gestão de RSU, e sugestões que podem nortear uma proposta para a implantação de um consórcio intermunicipal e referências.

\section{Metodologia}

Para realização deste estudo adotou-se abordagem qualitativa. Quanto à natureza, caracteriza-se como pesquisa aplicada por tratar de temas de interesse social. Esta pesquisa classifica-se como: descritiva, bibliográfica e documental, pois busca-se realizar um levantamento de informações relacionadas à área de estudo, assim como fatores legais que envolvem o tema do mesmo (Gerhardt \& Silveira, 2010).

$\mathrm{Na}$ busca de material bibliográfico para dar suporte a esse artigo, os autores, pesquisaram em bases de dados no período de março a julho de 2021, devido as inúmeras referências que abordavam a temática, essa pesquisa não se preocupou com particularidades sobre compostagem, incineração e reciclagem, mas sim, com uma revisão acerca da legislação que trata da adequada e, consequentemente, a criação de aterros sanitários nos âmbitos federal e estadual. Realizou-se levantamento bibliográfico de trabalhos que abordaram a aplicação da PNRS, e de que forma esta poderia ser implantada de maneira consorciada entre os municípios, considerando o viés econômico e logístico, além de possíveis recursos financeiros oriundos da União como incentivo à implantação de um aterro sanitário consorciado.

Realizou-se a descrição da região aqui analisada, utilizando a microrregião Teófilo Otoni/Malacacheta definida pela Secretaria de Estado de Saúde de Minas Gerais. Posteriormente, analisou-se o atual panorama da gestão dos RSU nos municípios que integram a região estudada, considerando a possibilidade de implantação de um consórcio intermunicipal com objetivo da criação de um aterro sanitário que possa atender a referida região. 


\section{Aspectos gerais na Gestão de Resíduos Sólidos Urbanos no Brasil}

Em âmbito federal, a legislação que trata e define as obrigações relacionadas à gestão de RSU é a Lei 12.305 de 2010 , intitulada Política Nacional de Resíduos Sólidos, a qual se sujeitam todas as pessoas físicas e jurídicas de direito público e privadas cujas atividades tenham por consequência a geração de RSU, ou ainda, as que desenvolvem atividades de gestão integrada e gerenciamento dos mesmos.

A PNRS, Lei 12.305/2010 traz a seguinte definição para RSU:

[...] material, substância, objeto ou bem descartado resultante de atividades humanas em sociedade, cuja destinação final se procede, se propõe proceder ou se está obrigado a proceder, nos estados sólido ou semissólido, bem como gases contidos em recipientes e líquidos cujas particularidades tornem inviável o seu lançamento na rede pública de esgotos ou em corpos d'água, ou exijam para isso soluções técnicas ou economicamente inviáveis em face da melhor tecnologia disponível (Brasil, 2010, p. sp).

Trindade e Riani (2016) em uma analogia à PNRS, relataram que a mesma tem por objetivo, além da integração entre os entes federativos, estaduais e municipais, a governança permeada pela estreita relação entre os entes públicos, privados e o consumidor, de maneira que a interação entre estes promova o desenvolvimento sustentável. Reforçam ainda:

A governança articulada busca por em prática uma ordem de prioridades na gestão e gerenciamento dos resíduos sólidos. Para ocorrer a não geração, a redução, a reutilização, a reciclagem, o tratamento e a disposição final ambientalmente adequada dos rejeitos, faz se necessária a criação de uma sinergia entre todos os atores que compõem o ciclo de vida do produto (Trindade \& Riani, 2016, p. 121).

Em seu artigo $19^{\circ}$, inciso III, a PNRS permite que seja verificada a possibilidade de implantação de soluções consorciadas entre os municípios, desde que observadas as variáveis: distância entre municípios, critérios de economia de escala e que sejam elaboradas formas de prevenção de riscos ambientais. A Lei 14.026 de 2020 , em seu artigo $11^{\circ}$ atualiza os prazos para adequação dos municípios em relação à disposição final adequada dos rejeitos gerados, sendo o período mais distante o dia 2 de agosto de 2024, para os municípios cuja população seja inferior a 50.000 habitantes no censo realizado no ano de 2010, pelo Instituto Brasileiro de Geografia e Estatística (IBGE) (Brasil, 2010).

No estado, a Lei 18.031 de 2009, denominada Política Estadual de Resíduos Sólidos, traz em seu artigo $6^{\circ}$ inciso VI, o princípio da destinação final ambientalmente adequada dos RSU e, em seu artigo $8^{\circ}$, apresenta como um de seus objetivos estimular soluções municipais e regionais na gestão integrada destes. Em seu artigo $22^{\circ}$ parágrafo $2^{\circ}$, a referida Lei identifica quem deverá elaborar a gestão integrada de RSU, e sugere a criação de consórcios intermunicipais, em concordância com a (PNRS) (Minas Gerais, 2009).

No Brasil, a disposição final de RSU ocorre majoritariamente por meio de lixões, aterros controlados e aterros sanitários, porém, em relação ao potencial poluidor dos RSU pós descarte, e comparando estas técnicas de destinação final, a que mais se adequa com o que prevê a legislação para destinação final destes, são os aterros sanitários (Araújo et al., 2020)

Brandão e Silva (2011), realizaram um estudo para identificar os impactos financeiros da implantação de aterros sanitários de maneira individualizada nos municípios e, relataram que quanto maior a população atendida, menores serão os custos referentes à disposição adequada dos resíduos e, deste modo, o consórcio intermunicipal na criação de aterros sanitários mostrou-se uma alternativa economicamente viável e ambientalmente adequada.

Poague (et al., 2018) concluíram após estudo realizado para identificar possíveis áreas de implantação de aterros sanitários, que além dos critérios técnicos, econômico-financeiros e sociais, o local de implantação dos mesmos deve atender as definições legais municipais de onde se pretende implantá-los, em conformidade com a NBR 8419/1992. Além disso, para implantação de consórcios intermunicipais, devem ser escolhidas áreas que apresentem localização estratégica do ponto de 
vista logístico, respeitando as diretrizes da PNRS.

Portella e Ribeiro (2014) ressaltam que os aterros sanitários são sistemas concebidos através de técnicas sanitárias de impermeabilização do solo, além de outros procedimentos que tem como objetivo final evitar que a deposição final dos RSU possa trazer prejuízos, como: mau cheiro, contaminação do lençol freático, proliferação de ratos e moscas, além da possível poluição visual ocasionada pelo amontoado de rejeitos expostos sobre o solo. Outra técnica importante para minimizar o acúmulo de RSU nos aterros sanitários consiste na criação de programas de coletas seletivas, esses programas podem representar uma "alternativa para diminuir os impactos ambientais causados pela geração de RSU, pois diminui a quantidade de entrada desses resíduos nos aterros, aumentando sua vida útil e retirando das ruas e lixões os resíduos." (Andrade et al., 2019, p. 11).

Nonato (et al., 2019) complementam que anexo às usinas de triagem, é comum a existência de unidades de compostagem da parcela orgânica dos RSU, é importante a separação prévia de resíduos orgânicos antes da etapa de triagem de recicláveis, pois sem a unidade de compostagem o trabalho nas usinas de triagem seria oneroso e não reduziria de forma expressiva o passivo ambiental.

Freitas (et al., 2019) afirmam que existe relação entre as características dos resíduos sólidos e efluentes domésticos gerados, e os hábitos e padrões de vida da população urbana. Dados da Associação Brasileira de Empresas de Limpeza Pública e Resíduos Especiais, elencados no panorama de resíduos sólidos do Brasil no ano de 2020, indicam o salto no volume de RSU gerados por ano no território brasileiro entre os anos de 2010 e 2019, passando de 67 para 79 milhões de toneladas por ano. Apesar do aumento populacional, o panorama indica o aumento da geração de resíduos per capita, partindo de $348 \mathrm{~kg} / \mathrm{ano}$ em 2010 para $379 \mathrm{~kg} / \mathrm{ano}$ em 2019 (Abrelpe, 2020).

Em seu artigo $18^{\circ}$, a PNRS estabelece que por meio da elaboração do plano municipal de gestão integrada de resíduos sólidos, torna-se possível a captação de recursos oriundos da união ou sob seu controle, encaminhados a empreendimentos e/ou serviços ligados à limpeza urbana e ao manejo de RSU. O mesmo artigo em seu parágrafo $1^{\circ}$ ressalta que os municípios que optarem por soluções consorciadas intermunicipais, ou ainda, que se inserirem de forma voluntária nos planos microrregionais de RSU, serão priorizados no acesso aos recursos da união (Brasil, 2010).

Deste modo fica explícita a importância da implantação dos aterros sanitários como ferramenta para a adequada destinação de rejeitos urbanos, inclusive em razão do aumento dos materiais gerados que em grande maioria não possuem a correta destinação. Os consórcios intermunicipais possibilitam menor aporte financeiro e redução dos impactos ambientais negativos. Assim, os "aterros compartilhados" representam uma alternativa para municípios com menores populações, ou mesmo que não detenham em seus territórios locais apropriados para implantação destes mecanismos.

\section{Descrições das Regiões de Planejamento do Governo do Estado de Minas Gerais}

Não incomum, as Unidades Federativas do Brasil, dividem seus territórios em Macro e Microrregiões, a fim de estabelecer critérios próprios de gestão, considerando principalmente, as particularidades regionais, dadas as grandes dimensões territoriais dos estados brasileiros. Atualmente, conforme a Secretaria de Planejamento e Gestão (SEPLAG), o Estado de Minas Gerais conta com 10 macrorregiões (Figura 1), sendo o município de Teófilo Otoni inserido na Região Jequitinhonha/Mucuri. Originalmente, previsto no projeto de Lei 1.590/93 (Minas Gerais, 2016), o critério das regiões passou a vigorar com o Plano Plurianual de Ação Governamental (PPAG) 1996/1999, adotado em dezembro de 1995.

A Região de Planejamento é ainda dividida pela SEPLAG em Meso e Microrregiões (Minas Gerais, 2016), sendo estas as menores delimitações regionais, onde são instaladas as Superintendências Regionais, a fim de possibilitar ao Estado maior fluidez nas decisões governamentais, bem como facilitar o acesso da população aos serviços, cujos trâmites faz-se necessária a presença física do cidadão. 
A Secretaria de Estado de Saúde de Minas Gerais (SESMG) através do Plano Diretor de Regionalização de Saúde de Minas Gerais (Minas Gerais, 2020), considerando a Mesorregião Jequitinhonha/Mucuri, divide o território em microrregiões, sendo o objeto deste estudo a microrregião intitulada Teófilo Otoni/Malacacheta. Esta microrregião conta com 13 municípios, sendo eles: Ataléia, Catuji, Franciscópolis, Frei Gaspar, Itaipé, Ladainha, Malacacheta, Novo Oriente de Minas, Ouro Verde de Minas, Pavão, Poté, Setubinha e Teófilo Otoni.

Figura 1 - Regiões de Planejamento do Estado de Minas Gerais.

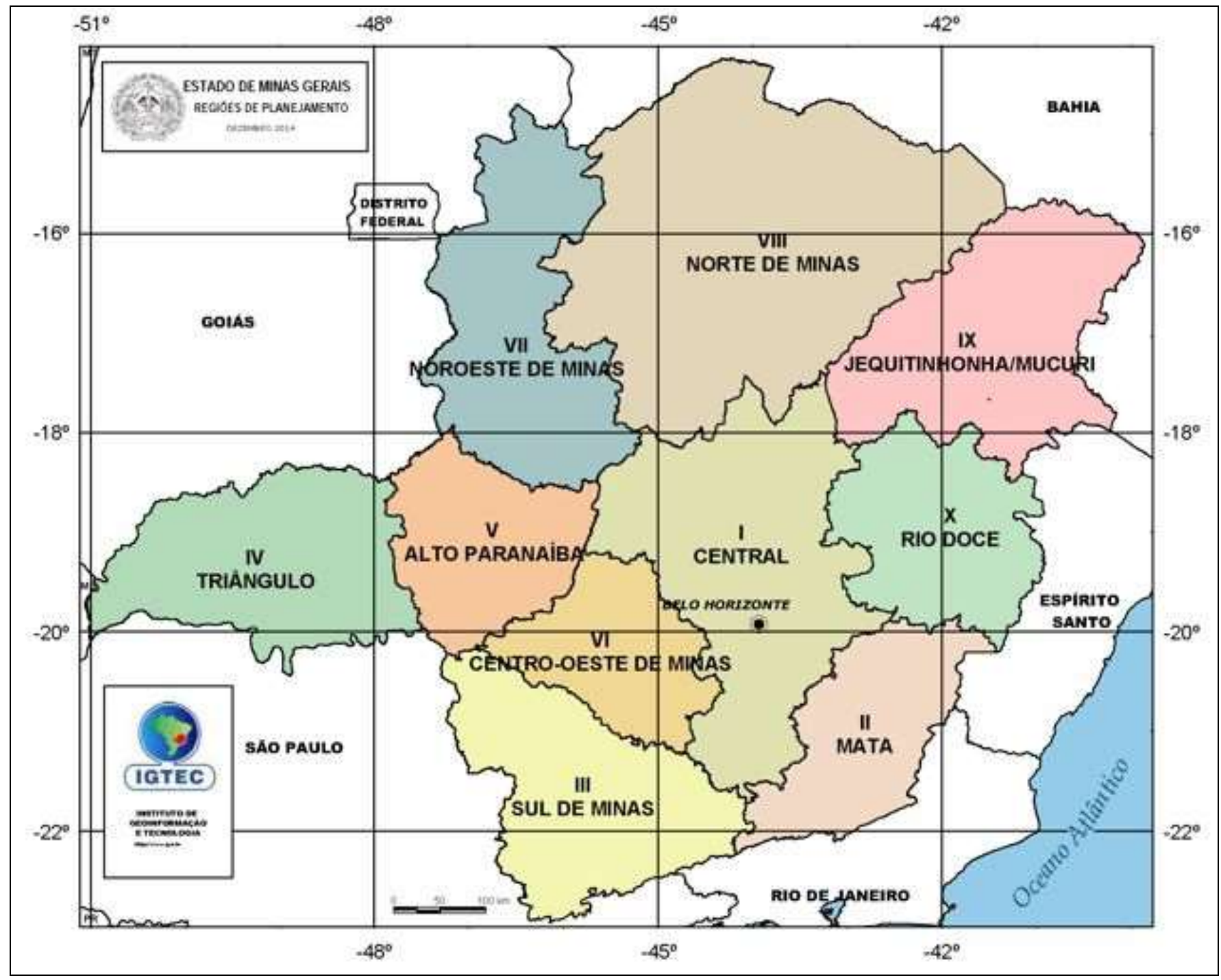

Fonte: Governo do Estado de Minas Gerais. Regiões de Planejamento (2021).

Todavia, em se tratando de um estudo propositivo, que busca a instalação de aterro sanitário, através de um consórcio intermunicipal, fez-se a opção por utilizar os municípios próximos a Teófilo Otoni, considerando a Microrregião de Saúde, adotados pelo Governo Estadual (Figura 2), conforme o Plano Diretor de Regionalização de Saúde de Minas Gerais (Minas Gerais, 2020) dadas as limitações que o distanciamento entre as cidades poderia impor a um aterro sanitário compartilhado, desde questões de custo operacional, bem como dos riscos ambientais envolvidos. 
Figura 2 - Microrregião de Saúde Teófilo Otoni/Malacacheta.

\section{Macrorregião: Nordeste Microrregião: Teófilo Otoni/Malacacheta}

Legenda:

(4) Polo Macro e Micro

A Polo Micro

- Município

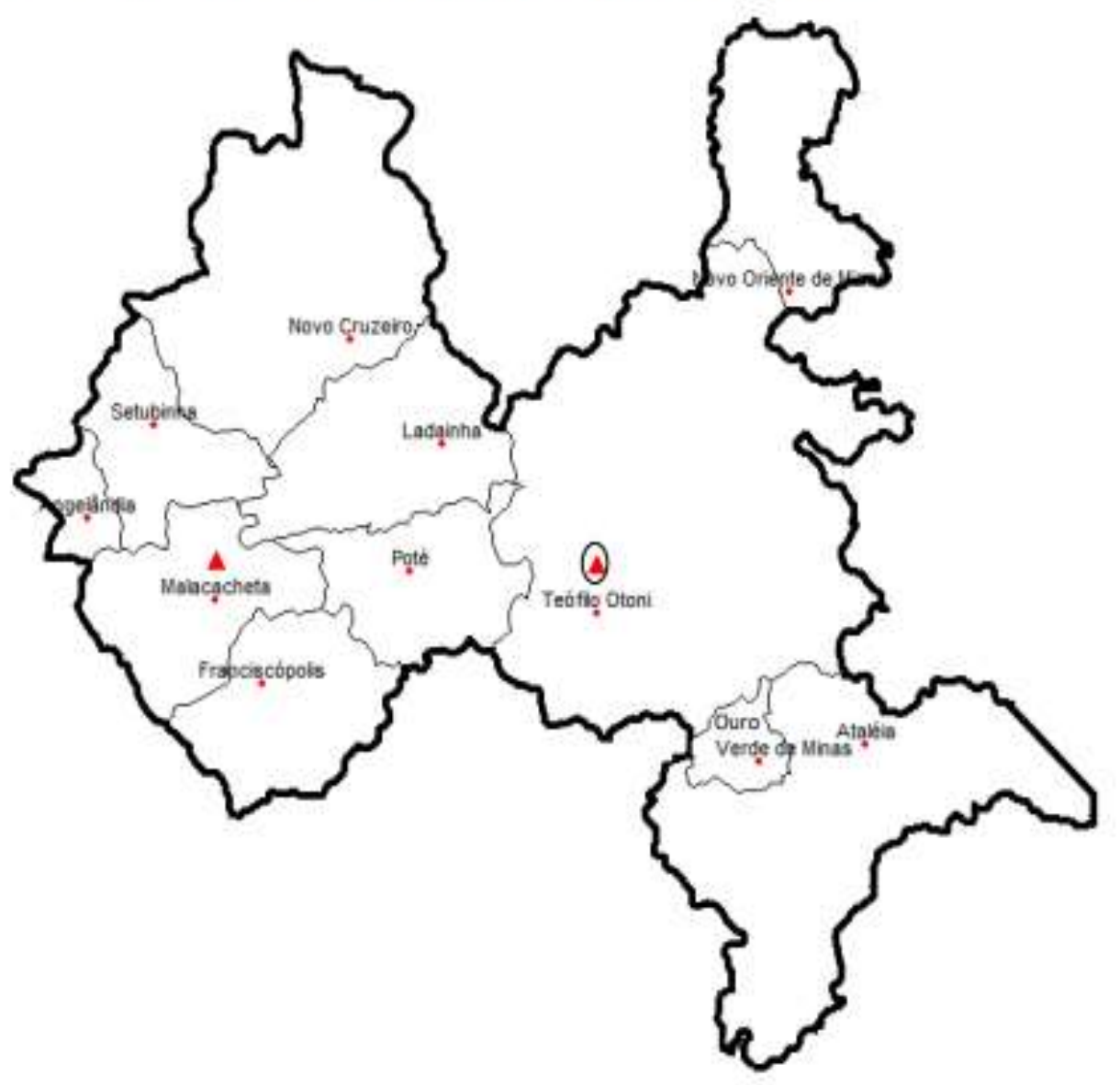

Fonte: SESMG. Plano Diretor de Regionalização de Saúde de Minas Gerais (2020).

Neste estudo, foi considerada a possibilidade de implantação de um aterro sanitário, através de um consórcio entre os municípios de Angelândia, Ataléia, Franciscópolis, Ladainha, Malacacheta, Novo Cruzeiro, Novo Oriente de Minas, Ouro Verde de Minas, Poté, Setubinha e Teófilo Otoni. Esses onze municípios totalizam 11364,6 km² em extensão territorial e 280.588 habitantes (Minas Gerais, 2020).

\section{A Análise dos Resultados}

Segundo o Relatório do Panorama da Destinação dos Resíduos Sólidos Urbanos no Estado de Minas Gerais, emitido pela Fundação Estadual de Meio Ambiente (FEAM) (Minas Gerais, 2018), foi verificado que em toda a região do Vale do Mucuri, dos 29 municípios do território, apenas 3 encaminham seus RSU de forma regularizada. Dessa forma, 26 municípios apresentam destinação irregular.

Segundo os dados da FEAM (2018):

- Os municípios de Itambacuri, Malacacheta e São José do Divino possuem destinação regularizada dos RSU com usinas de triagem e compostagem, atendendo $10,4 \%$ da população urbana;

- Os municípios Águas Formosas, Angelândia, Ataléia, Bertópolis, Campanário, Carlos Chagas, Catuji, Crisólita, Frei 
Gaspar, Fronteira dos Vales, Ladainha, Machacalis, Nanuque, Nova Módica, Novo Oriente de Minas, Ouro Verde de Minas, Pavão, Pescador, Poté, Santa Helena de Minas, Serra dos Aimorés, Setubinha, Teófilo Otoni e Umburatiba possuem a tipologia lixão como forma de destinação final dos RSU;

- Já os municípios Franciscópolis e Itaipé possuem a tipologia aterro controlado como forma de destinação final dos RSU.

O quantitativo de lixões e aterros controlados e a não existência de aterros sanitários, podem ocasionar problemas ambientais. Dessa forma, torna-se necessário investimentos públicos para implantação do aterro sanitário, daí a importância do consórcio com intuito do compartilhamento deste.

Acredita-se que a adesão do consórcio entre os municípios citados, tornaria os custos de operação por tonelada disposta e tratada, bem menor que a disposição em aterros individualizados, possibilitando que esses municípios com baixas arrecadações e poucos recursos para investimentos em políticas ambientais possam cumprir a legislação vigente.

\subsection{Consórcios para implantação de aterros sanitários}

Um dos obstáculos dos municípios de pequeno porte habitacional corresponde em realizar o tratamento adequado dos RSU, por se tratar de um método dispendioso. Diante das dificuldades de obter recursos financeiros ou mesmo técnicos suficientes para custear a destinação adequada para os resíduos, a PNRSU sugeriu alternativas para que os municípios possam escolher a forma mais apropriada para a regularização ambiental dos RSU. Dentre as sugestões da PNRSU, está a criação de aterros sanitários individuais ou compartilhados.

Com o intuito de incentivar a adoção de soluções compartilhadas para a gestão dos RSU nos municípios mineiros por meio da formação e operacionalização dos consórcios públicos, foi celebrado o termo de cooperação técnica (TCT) $\mathrm{N}^{\circ}$ 039/2018, entre o Ministério Público Estadual (MPMG), a Secretaria de Estado de Meio Ambiente e Desenvolvimento Sustentável (SEMAD) e a Fundação Estadual do Meio Ambiente (FEAM). O termo tem o objetivo de "promover ações conjuntas que viabilizem o fomento da implantação do gerenciamento e destinação adequada de RSU no âmbito do Estado de Minas Gerais, preferencialmente, por meio de consorciamento entre os municípios mineiros ” (FEAM, 2018, p. 140). A FEAM, dentre outras atividades, é o órgão responsável por coordenar a execução do Plano de Trabalho dos TCT.

Para a criação de um aterro sanitário é necessário apresentar um projeto de aterro sanitário de RSU de acordo com as normas da Associação Brasileira de Normas Técnicas (ABNT), mais especificamente, a NBR 8419/1992, que trata da correta acomodação dos RSU. A referida norma define aterro sanitário de RSU como:

Técnica de disposição de resíduos sólidos urbanos no solo, sem causar danos à saúde pública e à sua segurança, minimizando os impactos ambientais, método este que utiliza princípios de engenharia para confinar os resíduos sólidos à menor área possível e reduzi-los ao menor volume permissível, cobrindo-os com uma camada de terra na conclusão de cada jornada de trabalho, ou a intervalos menores, se necessário (ABNT/NBR 8419, 1992, p. 1).

A gestão compartilhada de RSU entre municípios via instituição de consórcios é uma das alternativas que vem sendo adotada para atender a PNRS. "O consorciamento permite que municípios vizinhos adotem soluções compartilhadas, com menor custo e maior potencial de sustentabilidade e é um dos instrumentos da PNRS que estabelece como diretriz para o enfrentamento de problemas ambientais, sociais e econômicos decorrentes do manejo inadequado de resíduos sólidos" (FEAM, 2016, on-line).

No ano de 2020, o Governo Federal destinou recursos do Fundo de Apoio à Estruturação de Projetos de Concessão e Parcerias Público-Privadas (FEP) da Caixa Econômica Federal para o desenvolvimento de projetos de gestão de RSU. No estado de Minas Gerais, ocorreram três habilitações de consórcios, que representam ao todo 57 municípios, e que tiveram o 
apoio direto da Secretaria de Estado de Meio Ambiente e Desenvolvimento Sustentável (Semad).Os três consórcios habilitados em Minas Gerais são: Consórcio Intermunicipal de Aterro Sanitário do Centro Oeste Mineiro (Cias Centro Oeste), que conta com 34 cidades; o Consórcio Intermunicipal de Tratamento de Resíduos Sólidos (Ecotres), do qual fazem parte as cidades de Conselheiro Lafaiete, Congonhas e Ouro Branco, na região central; e o Consórcio Público Intermunicipal de Desenvolvimento Sustentável do Triângulo Mineiro e Alto Paranaíba (Cides), formado por 20 cidades. No total 23 projetos foram habilitados no país, sendo estimado um repasse de 65 milhões para a elaboração dos mesmos.

Além do repasse de recursos da Caixa Econômica Federal, esta também vem prestando através de sua equipe de consultoria, apoio direto aos consórcios em todas as fases do desenvolvimento do projeto, desde os estudos preliminares, passando por estudos de viabilidade técnica, econômica e ambiental, até o processo licitatório da concessão.

Com este aporte de financiamento com recursos federais, verificou-se grande interesse de consórcios, que visavam apresentar projetos de gestão intermunicipal de resíduos, tanto que em março de 2021, através do Ministério do Desenvolvimento Regional, 10 consórcios, que reúnem 239 cidades mineiras, assinaram termo de cooperação com o Governo do Estado de Minas Gerais, para receberem assistência técnica na elaboração de projetos de gestão e manejo.

Cabe destacar, que terão prioridade para receber recursos financeiros da União, os municípios que escolherem soluções consorciadas intermunicipais, para gestão de RSU. Para tanto, deverão fomentar a coleta seletiva, com a participação de cooperativas ou outras formas de associação de catadores de materiais reutilizáveis e recicláveis formadas por pessoas físicas de baixa renda, conforme estabelece a Lei $\mathrm{n}^{\circ}$ 12.305/10, art. 18. O compartilhamento do destino final de RSU tem aumentado progressivamente em Minas Gerais, uma vez que vem sendo estimulado e reiterado desde a publicação da Deliberação Normativa COPAM No 52/2001 e, cada vez mais utilizada como requisito para acesso a projetos e recursos em todos os níveis de governança (FEAM, 2019).

O Consórcio Público Intermunicipal de Tratamento de Resíduos Sólidos (Ecotres), constituído no ano de 2005, pelos municípios de Congonhas, Conselheiro Lafaiete e Ouro Branco, em Minas Gerais, é um exemplo bem sucedido de tratamento adequado de RSU. De acordo com as informações contidas no site do consórcio, são atendidos mais de 200 mil habitantes das três cidades e mais 4 municípios conveniados, o que significa mais 140 mil habitantes, sendo coletadas 600 toneladas de resíduos por mês (Ecotres, 2019).

O Consórcio Ecotres é referência nacional no aspecto de iniciativa do poder público em resolver o problema do tratamento de resíduos sólidos. Conforme determinado no Protocolo de Intenções, o Consórcio tem "como finalidade planejar e executar ações, projetos, programas e políticas públicas que visem o tratamento de resíduos sólidos no âmbito dos três municípios consorciados" (Ecotres, 2019). Entre os principais benefícios da implantação deste projeto, destaca-se: "a disposição de forma adequada dos resíduos sólidos, a reintegração ambiental de parte dos componentes do lixo e a recuperação das áreas degradas pelo descarte inadequado dos resíduos” (Ecotres, 2019).

Outro modelo de consórcio encontra-se no Rio Grande do Sul, no município de Seberi. O Consórcio Intermunicipal de Gestão de Resíduos Sólidos (CIGRES) tem o objetivo de atender à demanda regional em relação aos resíduos sólidos e também possibilitar a implantação de novas tecnologias sustentáveis na região. O CIGRES iniciou-se em 2007, com 13 cidades e atualmente, já atende à 31 municípios da região Noroeste do Rio Grande do Sul, são eles: Ametista do Sul, Barra do Guarita, Boa Vista das Missões, Caiçara, Cerro Grande, Cristal do Sul, Derrubadas, Dois Irmãos das Missões, Erval Seco, Frederico Westphalen, Iraí, Jaboticaba, Lajeado do Bugre, Liberato Salzano, Miraguaí, Novo Tiradentes, Palmitinho, Planalto, Pinhal, Pinheirinho do Vale, Redentora, Rodeio Bonito, Sagrada Família, São José das Missões, São Pedro das Missões, Seberi, Taquaruçu do Sul, Tenente Portela, Vicente Dutra, Vista Alegre e Vista Gaúcha. A população atendida pelo referido consórcio, abrange cerca de 172.814 habitantes (CIGRES, 2019, p. 10).

Outra forma de solução compartilhada é a utilização de consórcios para a contração de aterros sanitários privados. O 
Consórcio Intermunicipal de Desenvolvimento Regional do Vale do Rio Grande (CONVALE) é uma "associação pública com múltiplas finalidades e duração indeterminada, que visa a integração econômica, social, política, técnica e administrativa dos municípios e a prática do associativismo municipal no Estado de Minas Gerais" (Consórcio Vital, 2020 p. 31). Os municípios participantes do consórcio são: Nova Ponte, Água Comprida, Campo Florido, Conceição das Alagoas, Pirajuba, Sacramento, Santa Juliana, Uberaba, Comendador Gomes, Planura, Delta, Veríssimo e Conquista. O consórcio atende cerca de 440.925 habitantes (Consórcio Vital, 2020). As parcerias públicas-privadas por meio da terceirização dos serviços surgiram como uma alternativa para melhorar o desempenho dos serviços a custos mais baixos.

As boas práticas em gestão de RSU ocorrem em vários municípios do Brasil e se combinadas à gestão municipal podem ser otimizadas, afirmando assim, a valorização e a sustentabilidade da prestação de serviços. Diante das possibilidades e particularidades de cada município, os gestores que ainda não regularizaram a destinação ambientalmente adequada dos RSU, devem escolher as opções de tratamento sugeridas pela PNRS, são elas: "a reutilização, reciclagem, compostagem, recuperação e o aproveitamento energético ou outras destinações admitidas pelos órgãos competentes [...]" entre elas a disposição final, observando normas operacionais específicas de modo a evitar danos ou riscos à saúde pública e à segurança e a minimizar os impactos ambientais adversos (LEI No 12.305/2010).

Os Resíduos de Serviços de Saúde (RSS) são partes importantes do total de RSU, não obrigatoriamente, pela quantidade gerada, mas pelo nível de riscos que reproduzem à saúde humana e ao meio ambiente. Esses resíduos necessitam de um descarte adequado, devido a essas particularidades, a gestão desses resíduos possui legislação própria. A Agência Nacional de Vigilância Sanitária (ANVISA), através da RDC ANVISA 306/2004 e o Conselho Nacional do Meio Ambiente (CONAMA), via Resolução CONAMA 358/2005, define como os RSS devem ser tratados. Conforme descrito nas referidas leis, compete a todo gerador de RSS elaborar o seu Plano de Gerenciamento de Resíduos de Serviços de Saúde (PGRSS), estabelecendo assim, às suas diretrizes de manejo dos RSS.

\section{Considerações Finais}

A partir das atuais legislações ambientais, fica clara a possibilidade para que os municípios elaborem projetos conjuntos para gestão e manejos de RSU, sendo observado um aumento de estudos propositivos regionais, para a implantação desses projetos em todo o território nacional trouxeram segurança jurídica, tanto aos entes públicos como privados, aumentando as fontes financiadoras destas, no sentido de proporcionar a universalização do acesso a modelos de gestão de RSU, principalmente aos pequenos municípios, cujos recursos financeiros são limitados.

Tendo em vista que na microrregião alvo deste estudo, apenas o município de Malacacheta possui aterro sanitário, associado às fragilidades socioeconômicas que impedem que cada município desempenhe adequadamente as atividades de gestão de resíduos na forma individualizada, evidencia-se a urgência pela elaboração de uma proposta intermunicipal de GIRSU, a fim de proporcionar uma parceria público e/ou privada que resolva o problema dos lixões nesta região em um curto espaço de tempo.

Inicialmente propõe-se uma estratégia de interlocução entre os gestores municipais, o que pode ser articulado pela Associação dos Municípios da Microrregião do Vale do Mucuri. Dentre as discussões para sensibilização dos gestores municipais, além das questões de sustentabilidade e meio ambiente, poderá ser elencado que além dos recursos recebidos pelo consórcio, oriundos do rateio entre os municípios, existem outras fontes de receita acessíveis. Nesse sentido, destaca-se a captação de recursos junto a outros entes federados, através de programas disponibilizados por entidades estaduais e federais com ações de fomento na área (ex: FUNASA, Ministério das Cidades, Ministério do Meio Ambiente, FEAM, emendas parlamentares, dentre outras). Em se tratando de um consórcio público de GIRSU, a PNRS, inclusive, assegura, em seu art. $8^{\circ}$, $\S 1^{\circ}$, inciso I, a priorização dos consórcios públicos intermunicipais no acesso aos recursos da União. 
A Educação Ambiental (EA), também deve ser uma prerrogativa nos municípios consorciados, tornando o cidadão protagonista das políticas de minimização de geração de resíduos e degradação ambiental, além de adotar postura crítica e transformadora da realidade sócio-política, podendo ser adotadas estratégias de campanhas de segregação de resíduos, possibilidade de compostagem com resíduos orgânicos, além de discussões em todos os níveis de ensino formal de maneira contínua e permanente, com proposições de projetos educacionais voltados à sustentabilidade.

As associações de catadores deverão ser estimuladas por políticas públicas que valorizem o trabalho dos mesmos, perante a sociedade e com financiamento de estruturas organizacionais, que permitam um ambiente seguro de trabalho, capacitações, bem como a otimização de custos com maior lucratividade e distribuição da renda oriunda desta atividade.

Este processo deve priorizar implantação ou melhoria da coleta seletiva nos municípios, sendo este o primeiro e mais importante passo para uma gestão de resíduos de qualidade, pois proporciona matéria prima para a cadeia dos processos de reciclagem e compostagem, além de diminuição de custos com o processo de segregação de resíduos e conscientização permanente da população.

Os consórcios apresentam-se, portanto, como uma possibilidade, sendo uma importante ferramenta de gestão e planejamento dos RSU e essa escolha cabe aos prefeitos. Devem ser levadas em conta a identificação de características socioeconômicas, culturais e estruturais dos municípios, a fim de definirmos estratégias comuns para a promoção de uma política microrregional de RSU, cabendo aos gestores alinhar as prioridades, os investimentos e seus respectivos repasses, proporcionando uma política integral de RSU, em prol não apenas de cumprir exigências legais no manejo de destinação final de RSU, mas principalmente, educar e proteger o meio ambiente da microrregião.

Com levantamentos realizados verifica-se a necessidade de elaboração de um projeto de GIRSU para a microrregião. Assim tornam-se necessárias novas pesquisas que contemplem, modelos pré-existentes de projetos, adaptando-os à região de estudo e levantamentos quantitativos dos RSU da microrregião Teófilo Otoni/Malacacheta que viabilizem a instalação de um consorcio intermunicipal.

\section{Referências}

Alves, N. F. (2019). Identificação de áreas para a implantação de aterro sanitário na mesorregião do Triângulo Mineiro/Alto Paranaíba com a utilização de geotecnologias. Dissertação Mestrado. https://repositorio.ufu.br/bitstream/123456789/25300/1/Identifica\%C3\%A7\%C3\%A3o\%C3\%81 reasImplanta\% $3 \% \mathrm{~A} 7 \% \mathrm{C} 3 \% \mathrm{~A} 30 . p d f$

Andrade, C. de S., Amaro, C. M., Oliver, L. A. C., Cordeiro, J., Alvarenga, C. A. de, Santos, C. I. F. dos, \& Cordeiro, J. L. (2019). Analysis of the management of solid urban waste in the city of Itabira (MG). Research, Society and Development, 8(3), e1983857. https://doi.org/10.33448/rsd-v8i3.857

Araújo, L. G. S. de, Ferreira, R. P. de S., Norberto, A. de S., Mariano, M. O. H., \& Callado, N. H. (2020). Temporal analysis of environmental parameters of the leachate from the landfill in Maceió-AL, Brazil. Research, Society and Development, 9(7), e594974435. https://doi.org/10.33448/rsd-v9i7.4435

Associação Brasileira de Empresas de Limpeza Pública e Resíduos Especiais. (2020). Panorama dos Resíduos Sólidos no Brasil. https://abrelpe.org.br/

Associação Brasileira de Normas Técnicas. (1992). NBR 8419 Apresentação de projetos de aterros sanitários de resíduos sólidos urbanos. http://www.ipaam.am.gov.br/wp-content/uploads/2021/01/NBR-8419-92-Apresentacao-de-Projetos-de-Aterros-Sanitarios-de-Residuos-Solidos-Urbanos.pdf

Brandão, A. O., \& Silva, G. N. (2011). Impactos Econômicos da Implantação de Aterros Sanitários Individuais nos Municípios Brasileiros. Revista Holos, 27(3). http://www2.ifrn.edu.br/ojs/index.php/HOLOS/article/view/586/449.

Brasil. (2020). Lei 14.026. Atualiza o marco legal do saneamento básico e altera a Lei nº 9.984, de 17 de julho de 2000 , para atribuir à Agência Nacional de Águas e Saneamento Básico (ANA) competência para editar normas de referência sobre o serviço de saneamento, a Lei ${ }^{\circ} 10.768$, de 19 de novembro de 2003, para alterar o nome e as atribuições do cargo de Especialista em Recursos Hídricos, a Lei n ${ }^{\circ} 11.107$, de 6 de abril de 2005, para vedar a prestação por contrato de programa dos serviços públicos de que trata o art. 175 da Constituição Federal, a Lei n 11.445 , de 5 de janeiro de 2007, para aprimorar as condições estruturais do saneamento básico no País, a Lei n ${ }^{\circ} 12.305$, de 2 de agosto de 2010, para tratar dos prazos para a disposição final ambientalmente adequada dos rejeitos, a Lei $\mathrm{n}^{\circ} 13.089$, de 12 de janeiro de 2015 (Estatuto da Metrópole), para estender seu âmbito de aplicação às microrregiões, e a Lei ${ }^{\circ}$ 13.529, de 4 de dezembro de 2017, para autorizar a União a participar de fundo com a finalidade exclusiva de financiar serviços técnicos especializados. http://www.planalto.gov.br/ccivil_03/_Ato2019-2022/2020/Lei/L14026.htm\#art11

Brasil. (2010). Lei 12.305. Institui a Política Nacional de Resíduos Sólidos; altera a Lei no 9.605, de 12 de fevereiro de 1998 ; e dá outras providências. http://www.planalto.gov.br/ccivil_03/_Ato2007-2010/2010/Lei/L12305.htm.

Brasil. (2020). Ministério do Meio Ambiente. Secretaria de Qualidade Ambiental. Plano Nacional de Resíduos Sólidos. http://consultaspublicas.mma.gov.br/ 
planares/wp-content/uploads/2020/07/Plano-Nacional-de-Res\%C3\%ADduos-S\%C3\%B3lidos-Consulta-P\%C3\%BAblica.pdf

Cigres. (2019). Consórcio Intermunicipal de Gestão de Resíduos Sólidos. Plano Intermunicipal de Gestão Integrada de Resíduos Sólidos: relatório final. http://cigres.com.br/portal/?mn=prgirs

Feam. (2017). Fundação Estadual do Meio Ambiente. Panorama da Destinação dos Resíduos Sólidos Urbanos. http://www.feam.br/images/stories/2017/ RESIDUOS/Minas_Sem_Lixoes/Relat\%C3\%B3rio_de_Progresso_2017_-_PANORAMA_RSU_FINAL_Ano_base_2016.pdf

Feam. (2018). Fundação Estadual do Meio Ambiente. Panorama da destinação dos resíduos sólidos urbanos no Estado de Minas Gerais em 2017. http://www.feam.br/images/stories/2018/RESIDUOS/MINAS_SEM_LIXOES/Relat\%C3\%B3rio_de_Progresso_2018_PANORAMA_RSU_Ano_base_2017 _FINAL-_junho_2018.pdf

FEAM. Fundação Estadual do Meio Ambiente. Panorama da destinação dos resíduos sólidos urbanos no Estado de Minas Gerais em 2018. (2019). http://www.feam.br/images/stories/2019/MINAS_SEM_LIXOES/Relat\%C3\%B3rio_de_Progresso_2019_-_PANORAMA_RSU_Ano_base_2018_v_1912.pdf

Ferreira, V. A., \& Tambourgi, E. B. (2009). A importância do gerenciamento de resíduos sólidos urbanos. Exacta, 7(2), 157-163, 2009. https://periodicos.uninove.br/exacta/article/viewFile/1633/1582

Freitas, L. C. F., Santiago, Y. C., Ribeiro, N. de S., Marques, T. E., Pinto, J. A., Nieto Mogollón, D. I., \& Silva, A. T. Y. L. (2019). Economic feasibility and the energetic potential from landfill gas in Campinas - SP. Research, Society and Development, 8(6), e4286788. https://doi.org/10.33448/rsd-v8i6.788

Gerhardt, T. E., \& Silveira, D. T. (2009). Métodos de pesquisa. Porto Alegre, Brasil: Editora da Universidade Federal do Rio Grande do Sul (UFRGS). http://www.ufrgs.br/cursopgdr/downloadsSerie/derad005.pdf

IPEA. (2015). Boas Práticas de Gestão de Resíduos Sólidos Urbanos e de Logística Reversa com a Inclusão de Catadoras e de Catadores de Materiais Recicláveis: relatório de pesquisa.

Kneipp, J. M. et al. (2012). Gerenciamento de Resíduos Sólidos Urbanos: um estudo em municípios do estado do Rio Grande do Sul. Redes. 17 (2) p. 175 194. http://dx.doi.org/10.17058/redes.v17i2.2055

Lei 11.107 (2005). Lei dos Consórcios Públicos e da Gestão Associada de Serviços Públicos. http://www.planalto.gov.br/ccivil_03/_ato20042006/2005/lei/111107.htm

Minas Gerais. (2009). Lei 18.031. Dispõe sobre a Política Estadual de Resíduos Sólidos. http://www.siam.mg.gov.br/sla/download.pdf?idNorma=9272

Minas Gerais. (2016). Secretaria de Planejamento e Gestão. Meso e Microrregiões do IBGE. https://www.mg.gov.br/sites/default/files/paginas/arquivos /2016/ligminas_10_2_04_listamesomicro.pdf.

Minas Gerais. (2011). Secretaria de Estado da Saúde. Plano Diretor de Regionalização de Saúde de Minas Gerais. http://vigilancia.saude.mg.gov.br/index. $\mathrm{php} /$ download/livro-plano-diretor-de-regionalizacao-pdr-sus-mg/?wpdmdl=3112

Minas Gerais. (2010). Secretaria de Planejamento e Gestão. Regiões de Planejamento. https://www.mg.gov.br/conteudo/conheca-minas/geografia/regioes-deplanejamento.

Notato, C. G. da S., Sousa, E. R. de, \& Gontigo, H. M. (2019). Implantation of a Recycling Plant in the city of Rio Piracicaba-MG. Research, Society and Development, 8(3), e2683751. https://doi.org/10.33448/rsd-v8i3.751

Olivo, V. D.; Dal Bello, M. C. (2019). Boas Práticas na Gestão Integrada de Resíduos Sólidos Urbanos em Municípios Brasileiros. Revista TcE Contas. 1 (1), p. 151-167. http://tce.to.gov.br/revista/index.php/tcecontas/article/view/4/15

Plano de Gerenciamento Integrado de Resíduos Sólidos do Consórcio Intermunicipal Rides - Região Integrada de Desenvolvimento Sustentável (2015). http://indianopolis.mg.gov.br/wp-content/uploads/2020/08/pgirs-rides-volume-i.pdf

Poague, K. I. H.M., Silva, W. R., Resende, V. M., Pereira, A. P. M., \& Árabe, M. P. (2017). SIG na seleção de áreas para implantação de aterros sanitários: estudo de caso em Jundiaí - SP. (2018). Revista D.A.E. 66 (213). DOI: 10.4322/dae.2018.032.

Portella, M. O., \& Ribeiro, J. C. J. (2014). Aterros sanitários: aspectos gerais e destino final dos resíduos. Revista Direito Ambiental e sociedade, 4 (1), 115134. http://www.ucs.br/etc/revistas/index.php/direitoambiental/article/view/3687/2110

Secretaria de Estado de Meio Ambiente. (2019). Fundação Estadual de Meio Ambiente. Panorama da Destinação dos Resíduos Sólidos Urbanos no Estado de Minas Gerais, do ano de 2018. http://www.feam.br/images/stories/2019/MINAS_SEM_LIXOES/Relat\%C3\%B3rio_de_Progresso_2019__PANORAMA_RSU_Ano_base_2018_v_1912.pdf

Secretaria de Estado de Saúde de Minas Gerais. (2020) Subsecretaria de Gestão Regional. Ajuste do Plano Diretor de Regionalização de Saúde de Minas Gerais $(P D R / M G)$. http://www.saude.mg.gov.br

Trindade, A. G., \& Riani, R. S. R. (2016). Gestão consorciada de resíduos sólidos: um instrumento de integração e promoção do desenvolvimento sustentável. Revista de Direito e Sustentabilidade. DOI: 10.21902 